\title{
Primary double tooth with partial anodontia of permanent dentition - a case report
}

\author{
V. Arun Prasad Rao ${ }^{1}$, N.Venugopal Reddy ${ }^{2}$, R. Krishnakumar ${ }^{1}$, D.K. Sugumaran ${ }^{3}$, G. Mohan ${ }^{3}$, A.R. Sen- \\ thil Eagappan ${ }^{4}$
}

${ }^{1}$ MDS,Professor, Department of Pedodontics and Preventive Dentistry, Rajah Muthiah Dental College and Hospital, Annamalai University.

${ }^{2}$ MDS, Professor and HOD, Department of Pedodontics and Preventive Dentistry, Rajah Muthiah Dental College and Hospital, Annamalai University.

${ }^{3}$ MDS, Reader, Department of Pedodontics and Preventive Dentistry, Rajah Muthiah Dental College and Hospital, Annamalai University.

${ }^{4}$ Post Graduate student, Department of Pedodontics and Preventive Dentistry, Rajah Muthiah Dental College and Hospital, Annamalai University.

Correspondence:

Dr. V. Arun Prasad Rao, MDS,

Professor,

Division of Pedodontics and Preventive Dentistry,

Rajah Muthiah Dental College and Hospital,

Annamalai University, Annamalai Nagar,

Chidambaram- 608002 (INDIA)

e-mail-arunprasadrao@yahoo.com

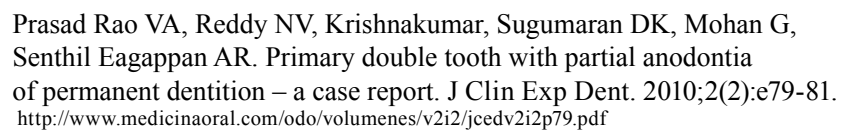

Prasad Rao VA, Reddy NV, Krishnakumar, Sugumaran DK, Mohan G, Senthil Eagappan AR. Primary double tooth with partial anodontia of permanent dentition - a case report. J Clin Exp Dent. 2010;2(2):e79-81. http://www.medicinaoral.com/odo/volumenes/v2i2/jcedv2i2p79.pdf

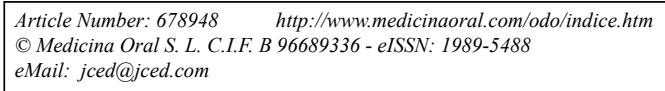

eMail: jced@jced.com

\begin{abstract}
Dental anomalies of number and forms may occur in the primary and permanent dentition. Various terms have been used to describe dental twinning anomalies: gemination, fusion, concrescence, double teeth, cojoined teeth, twinned teeth, geminifusion and vicinifusion. Double tooth is a term used to describe connate tooth and includes both dental fusion and gemination. The phenomenon of gemination occurs when two teeth develop from one single bud leading to a larger tooth. Fusion is a condition in which the crowns of two separate teeth have been joined together during the crown development. Fusion occurs infrequently but could cause esthetic, spacing and periodontal problems. The present article highlights the presence of a primary double tooth in an 11 year old boy involving primary mandibular left lateral incisor and canine. Clinical examination and radiographic examination confirmed the absence of the permanent left mandibular lateral incisor. Cases with primary double tooth necessitate careful examination as they may be associated with anomalies in the succeeding permanent dentition and require proper treatment planning.
\end{abstract}

Key words: Double tooth, fusion, gemination, partial anodontia, primary dentition. 


\section{Introduction}

Dental anomalies in primary dentition are frequently observed during routine dental examination, leading to orthodontic problems, including spacing or crowding of teeth, loss of arch length, deviation of the midline, increased caries risk, and esthetic problems in preschool children (1). Fusion is one of the most common anomalies in the primary dentition and has a familial tendency (2). Fusion has also been reported with congenital anomalies like cleft lip (3). It is also seen with X-linked congenital conditions (4). Dental fusion has been defined as the partial or complete union, during development, of two or more adjacent teeth. Fusion can occur between two normal teeth or between a normal tooth and a supernumerary tooth. Dental fusion results in one tooth less than normal (5). This developmental anomaly is most often confused with gemination. However, a differential diagnosis can be made radiographically. In cases of fusion, the crowns are united by enamel and/or dentine, but there are two roots or two root canals in a single root. In contrast, in gemination, the structure most often presents two crowns, either totally or partially separated, with a single root and one root canal (6). The present article describes a clinical case of double tooth with partial anodontia of permanent dentition.

\section{Case Report}

An 11-year-old boy reported with a complaint of broken upper left front tooth. There was a history of trauma 2 months ago. The extraoral examination findings were non contributory. The intraoral examination revealed the presence of following teeth:

161514131211212223242526 474685444342413172733334753637

The permanent maxillary left central incisor revealed crown fracture involving enamel and dentin. The primary mandibular left lateral incisor and canine were fused (Fig. 1). Parental history was negative to familial tendency to fused teeth. The permanent mandibular left canine was in linguoversion (Fig.2). A provisional diagnosis of Ellis and Davies class II fracture of permanent maxillary left central incisor and primary double tooth involving fusion of primary mandibular left lateral incisor and canine was made. The intraoral periapical radiograph of the maxillary left anterior region and pulp vitality tests indicated that permanent maxillary left central incisor was vital. The intraoral periapical radiograph of the mandibular left anterior region confirmed that the primary lateral incisor and canine were fused and permanent mandibular left lateral incisor was absent (Fig. 3). Radiographic and vitality tests confirmed the diagnosis. The treatment plan included pulp capping of fractured permanent maxillary left central incisor with calcium hydroxide followed by composite resin restoration. The patient and the parent were informed about the absen-

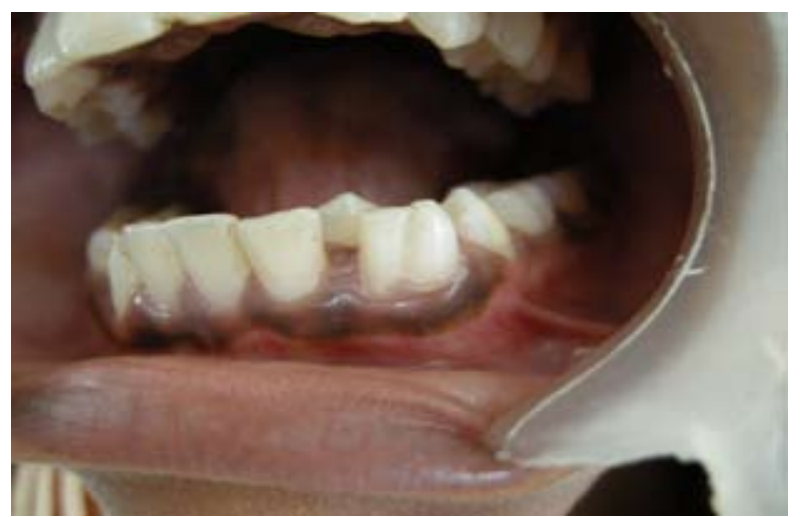

Fig.1. Labial view showing fused primary mandibular left lateral incisor and canine

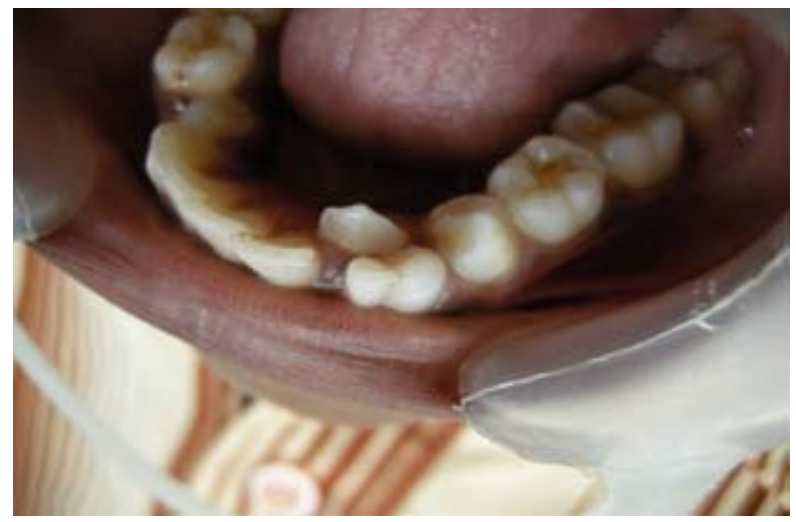

Fig.2. Occlusal view showing fused primary mandibular left lateral incisor and canine

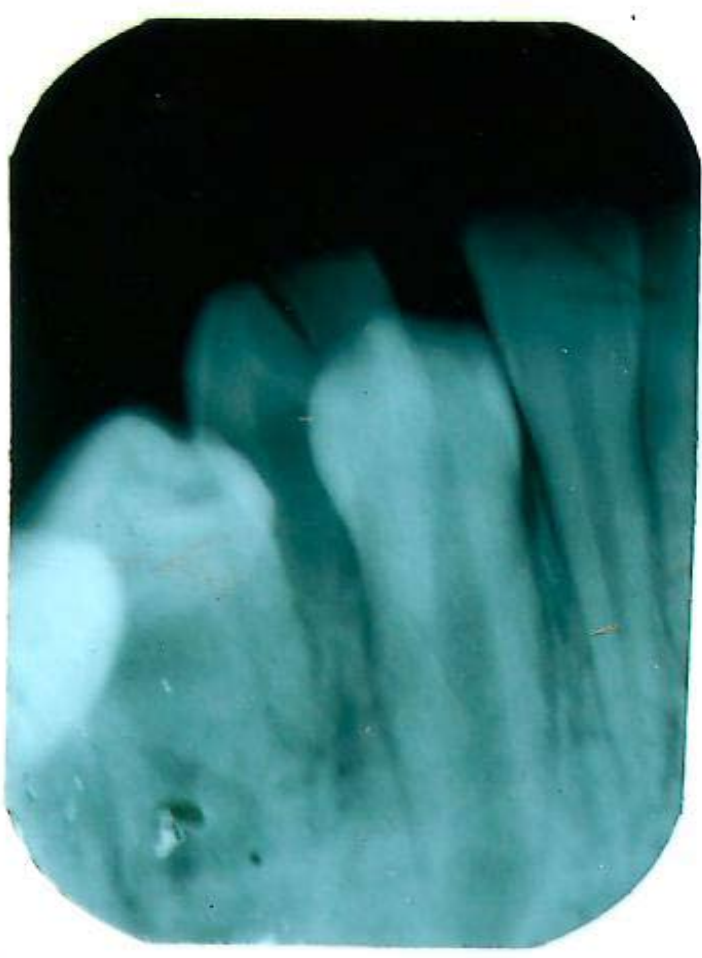

Fig.3. Intraoral periapical radiograph showing two separate root canals in primary mandibular left lateral incisor and canine 
ce of permanent mandibular lateral incisor and oriented about the preservation of primary tooth. Periodic review was advised for pulp vitality tests for fractured tooth and space management and orthodontic correction of linguoverted permanent mandibular left canine.

\section{Discussion}

Prevalence of tooth fusion was estimated at $0.5 \%$ to $2.5 \%$ in the primary dentition, whereas prevalence in the permanent dentition seemed to be clearly lower than in the primary dentition (7). Due to this low prevalence, the importance of these anomalies tends to be underestimated (8).

When fusion occurs, the clinician must be aware of following major dental concerns. First, since fused teeth are clearly wider than the surrounding teeth, esthetics may be a concern. In the present case, the esthetic view was not a problem in primary dentition and the family was uninformed on the fused teeth until the patient visited the dental clinic.

Second, when normal teeth fuse, excess dental space can result. This occurs because two fused teeth require less space in the dental arch than two normal teeth. A visible diastema was present in this case between the fused teeth and the adjacent central incisor.

Third concern relates to both esthetics and occlusion because of missing permanent teeth. When fusion occurs in the primary dentition, some of the permanent incisors are not present. This problem requires both cosmetic and orthodontic consideration. In this case the left permanent mandibular lateral incisor was absent.

The final concerns involve their surface contour. Fused teeth commonly exhibit labial and lingual grooves running vertically on the crown surface. These grooves are very pronounced in cases of incomplete fusion. These grooves are difficult to clean and caries may result (9). In the present case there was a complete fusion. Although grooves were present on the tooth surface, no caries was detected.

The incidence of double tooth in worldwide populations ranges from 0.14 to $5.0 \%$ with no sex predilection, and unilateral expression is more common than bilateral expression. Double tooth occurs most in the mandibular anterior region in primary dentition and most commonly unilaterally in the mandibular lateral incisor and canine region (10).

Gellin (11) reported that when the number of primary anterior teeth was reduced by one, hypodontia of one more permanent lateral incisor was observed in $100 \%$ of cases when double tooth involved lateral incisor and canine. However when the double tooth involved central and lateral incisors, only $37.5 \%$ of the cases presented with missing permanent successors. Gellin (11) also reported that when the number of primary anterior teeth remained the same, no effect on the number of the permanent succedaneous anterior teeth was observed. The presence of primary double tooth could also cause delayed resorption of root due to greater root mass and increased area of root surface relative to the size of the permanent successor crown. This may lead to delayed or ectopic eruption of the permanent successor. Therefore, early diagnosis of the anomaly is of considerable importance.

Treatment of a fused tooth will depend on the clinical situation. If the tooth is free from caries, it may require no special treatment. General preventive advice should be given to the parent and the child (6), and if caries already exists, a restoration should be performed in order to retain function and aesthetics (12). If there is pulpal involvement, endodontic treatment should be carried in the same way as for a multirooted tooth (13).

Dental fusion and gemination are asymptomatic, but both can result in a number of dental difficulties including tooth reduction in the permanent successors, increased susceptibility to subgingival bacterial plaque, aplasia or malformation of the permanent successors and dental impaction. To establish a right treatment to this anomaly, the proper examination and knowledge to recognize this anomaly is a prerequisite.

\section{References}

1. Yuen SW, Chan JC, Wei SH. Double primary teeth and their relationship with the permanent successors: a radiographic study of 376 cases. Pediatr Dent. 1987;9:42-8.

2. Hagman FT. Fused primary teeth: a documented familial report of case. ASDC J Dent Child. 1985;52:459-60.

3. Meadors LW, Jones HL. Fused primary incisors with succedaneous supernumerary in the area of a cleft lip: case report. Pediatr Dent. 1992;14:397-9.

4. Golabi M, Ito M, Hall BD. A new X-linked multiple congenital anomalies/mental retardation syndrome. Am J Med Genet. 1984;17:36774.

5. Tasa GL, Lukacs JR. The prevalence and expression of primary double teeth in western India. ASDC J Dent Child. 2001;68:196-200.

6. Alvarez I, Creath CJ. Radiographic considerations for supernumerary tooth extraction: report of case. ASDC J Dent Child. 1995;62:141-4.

7. Hülsmann M, Bahr R, Grohmann U. Hemisection and vital treatment of a fused tooth--literature review and case report. Endod Dent Traumatol. 1997;13:253-8.

8. Nik-Hussein NN, Abdul Majid Z. Dental anomalies in the primary dentition: distribution and correlation with the permanent dentition. J Clin Pediatr Dent. 1996;21:15-9.

9. Alpöz AR, Munanoğlu D, Oncag O. Mandibular bilateral fusion in primary dentition: case report. J Dent Child (Chic). 2003;70:74-6.

10. Brook AH, Winter GB. Double teeth. A retrospective study of 'geminated' and 'fused' teeth in children. Br Dent J. 1970;129:123-30.

11. Gellin ME. The distribution of anomalies of primary anterior teeth and their effect on the permanent successors. Dent Clin North Am. 1984;28:69-80.

12. Knapp JF, McMahon JI. Treatment of triple tooth: report of case. J Am Dent Assoc. 1984;109:725-7.

13. Santos LM, Forte FD, Rocha MJ. Pulp therapy in a maxillary fused primary central incisor--report of a case. Int J Paediatr Dent. 2003;13:274-8. 